\title{
Viabilidade Econômica do Biogerador tipo Marinha na Fazenda de Cacau
}

\section{Economic Viability of the Marine Biogenerator at the Cocoa Farm}

Article Info:

Article history: Received 2021-02-01 / Accepted 2021-02-25 / Available online 2022-02-25 doi: $10.18540 /$ jcecvl8iss2pp13949-01e

\author{
Rafaela Cristina Ferreira Brito \\ ORCID: https://orcid.org/0000-0002-5347-685X \\ Universidade Estadual de Santa Cruz, Brasil \\ E-mail: rcfbrito@uesc.br \\ Jorge Henrique de Oliveira Sales \\ ORCID: https://orcid.org/0000-0003-1992-3748 \\ Universidade Estadual de Santa Cruz, Brasil \\ E-mail: jhosales@uesc.br
}

\section{Resumo}

Apesar do cenário adverso ao crescimento econômico, a demanda por energia continua crescendo e consolidando-se como uma área promissora para investimentos. Nessa perspectiva, este trabalho visa analisar a viabilidade econômica para a cogeração ou autonomia energética da produção de eletricidade em um cenário particular de uma fazenda de cacau, por meio de um biodigestor rural modelo da Marinha, em um estudo de caso realizado na cidade de Barro Preto, Bahia. Os parâmetros para verificação da viabilidade econômica e energética são analisados em relação ao sistema gerador de energia e elementos construtivos do biodigestor. Os indicadores econômicos de viabilidade demonstram valores promissores quantos aos benefícios obtidos com a substituição da carga de energia comprada da concessionária pela gerada no sistema, proveniente do biogás, mostrando que o empreendimento pode ser considerado viável.

Palavras-chave: Eficiência energética. Análise econômica. Rejeitos.

\begin{abstract}
Despite the adverse scenario for economic growth, the demand for energy continues to grow and consolidates itself as a promising area for investments. In this perspective, this work aims to analyze the economic feasibility for cogeneration or energy autonomy of electricity production in a particular scenario of a cocoa farm, through a rural biodigester model of the Navy, in a case study carried out in the city of Barro Preto, Bahia. The parameters for verifying the economic and energy viability are analyzed in relation to the energy generating system and constructive elements of the biodigester. The economic viability indicators show promising values regarding the benefits obtained from replacing the energy load purchased from the concessionaire with the one generated in the system, derived from biogas, showing that the project can be considered viable.
\end{abstract}

Keywords: Energy efficiency. Economic analysis. Waste. 


\section{Introdução}

A maioria dos países, desenvolvidos ou não, têm promovido ações em maior ou menor quantidade para que as fontes de energia renováveis, com capacidade regeneração para curto e médio prazo, possuam uma participação mais efetiva em suas matrizes energéticas (CORTEZ et. al, 2008). O Brasil já é um dos destaques na área de apostas em energias renováveis, liderando o ranking da matriz de geração de eletricidade com fontes renováveis (como a biomassa e as fontes hídricas) dos países que integram o bloco dos BRICS com expressivos $80,4 \%$. O valor supera o indicador do bloco com 25,3\% em mais de 1/3, segundo dados do boletim anual "Energia no bloco dos BRICS", para o ano de 2016. Essas informações revelam a amplitude das aplicações e demandas de diversificação da matriz energética atual e se refletem também no âmbito regional.

De acordo com o Boletim de Conjuntura Econômica e Social, referente ao último trimestre de 2019, a microrregião de Ilhéus-Itabuna registrou uma evolução da demanda de energia em suas atividades econômicas em comparação com o ano anterior. Ocorrendo um incremento de 12,8\%, para o setor de comércio e serviços, no município de Ilhéus, seguido por uma variação de 7,8\% para o munícipio de Itabuna, no mesmo setor. (CACES, 2019). Dados que revelam que apesar do cenário adverso ao crescimento econômico, a demanda por energia continua crescendo e consolidando-se como uma área promissora para investimentos no que tange às formas alternativas de obtenção de energia elétrica ou gestão de energia.

Diante deste cenário, a biomassa se apresenta como uma solução tecnológica de grande potencial gerador de energia, apontando um valor de 52.267 GWh na geração de eletricidade no Brasil para o ano base de 2018, segundo Balanço Energético Nacional (BEN, 2019). Além da grande versatilidade em poder ser utilizada em substituição aos combustíveis convencionais e na geração de energia elétrica, esta pode ser encontrada em "toda matéria de origem vegetal existente na natureza ou gerada pelo homem ou animal" (SALOMON; FILHO, 2007, p. 4). A principal forma de utilização dessa biomassa se dá por meio da conversão biológica, realizada através das bactérias anaeróbicas no interior de biodigestores, onde o gás metano $(\mathrm{CH} 4)$ é produzido (principal componente do biogás) em conjunto com o dióxido de carbono (CO2) e outros gases em menores quantidades.

Dessa forma, partindo de uma ótica de gestão energética e aproveitamento de resíduos, esse trabalho busca analisar a viabilidade econômica para a cogeração ou autonomia energética da produção de eletricidade em um cenário particular de uma fazenda de cacau, por meio de um biodigestor rural modelo da Marinha, em um estudo de caso realizado na cidade de Barro Preto, Bahia (BRITO, 2021). Modelos matemáticos foram construídos para o cacau (SALES e SUZUKI, 2021) e cupuaçu (SALES e LIMA, 2020).

\section{Biodigestor}

O local de execução desse trabalho é a Fazenda São José, localizada no município de Barro Preto, Bahia. A Fazenda mantém a tradição de cacauicultores da região desde 1986, contando com uma área de cultivo de cacau de 36,50 hectares (ha), uma área de pasto de 16,93 ha e demais áreas com benfeitorias. Espera-se que esta propriedade seja a primeira unidade rural do Sul da Bahia a dispor de um biodigestor para a geração de energia elétrica. O projeto básico está sendo realizado em parceria com a FAPESB (Fundação de Amparo à Pesquisa do Estado da Bahia) e empresa Legon, localizada em Santa Rita, Minas Gerais, que tem desenvolvido equipamentos eletrônicos para controle de variáveis, temperatura e umidade, em biodigestores no sudeste do país.

O material disponível para ser utilizado como substrato na digestão anaeróbica dentro do biodigestor conta com resíduos orgânicos gerados pela população rural da propriedade e os resíduos vegetais gerados pelas atividades agropecuárias (cultivos, criações de animais, beneficiamento, processamento e outros oriundos da mesma fonte), como exemplo a casca de cacao (Sales e Brito, 2022). 
A expectativa é a construção de um biodigestor Modelo da Marinha (Figura 1), de processo descontínuo, à batelada, com capacidade de suprimento do consumo médio de energia da população e reaproveitamento dos dejetos, gerando mais economia e menor impacto ambiental.

Estima-se um volume médio de $850 \mathrm{~m} 3$ para o biodigestor, o que equivale a cerca de $34 \%$ do volume de uma piscina olímpica de $2500 \mathrm{~m} 3$. Para sua instalação e construção, são determinadas as dimensões externas de $20 \times 17$ metros, profundidade de 2,5 metros (Figura 1), sendo coberto por uma geomembrana flexível (gasômetro) de policloreto de vinila (PVC). A construção é feita sobre uma fundação direta contínua, que requer os serviços inicias de terraplanagem e escavação, além das tubulações de PVC responsáveis por conduzir o fluxo de entrada e saída dos resíduos no biodigestor e para transporte do biogás.

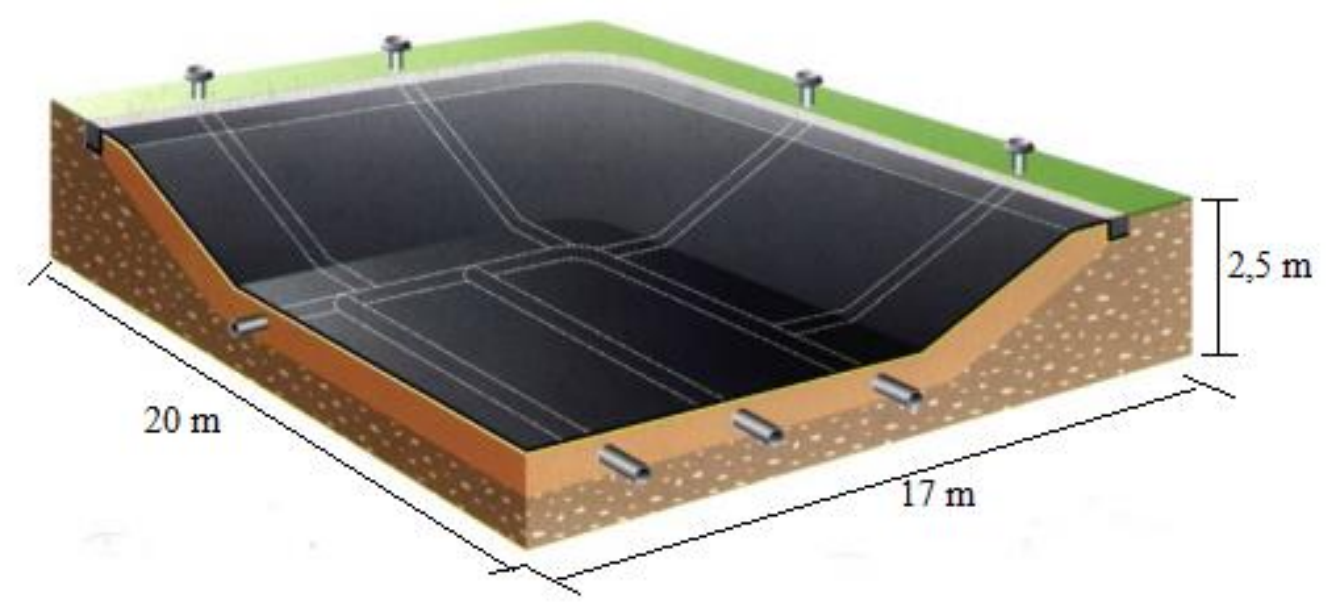

Figura 1 - Dimensões estimadas para o biodigestor modelo da Marinha. Fonte: Brito (2021).

\section{Biogás e Conversão Energética}

O biogás produzido no interior do biodigestor será utilizado como combustível para geração de energia elétrica por meio de um motor de combustão interna acoplado a um gerador de eletricidade, que fará ao processo de conversão de energia. Dessa forma, para escolha do sistema de geração de energia elétrica é preciso levar em conta parâmetros dimensionais dos equipamentos, que envolvem a eficiência do motor gerador, o tempo de utilização da planta de geração e a disponibilidade diária de biogás junto ao seu poder calorífico.

Em função da disponibilidade de dejetos ao biodigestor na localidade estudada e de simulações numéricas analisadas foi verificado um volume de produção de biogás convergente de $163 \mathrm{~m} 3$, utilizando dejetos bovinos, esgoto doméstico e casca de cacau como substrato (BRITO; SALES, 2019). Leva-se em conta que esse volume de biogás esteja disponível diariamente para ser usado na alimentação do carburador e consequentemente do motor de combustão interna. Essa dosagem é realizada através da válvula reguladora de fluxo, presente no carburador, e dos comandos emitidos pelo sistema eletrônico de monitoramento do biodigestor.

Tendo em vista a demanda diária de biogás estimada e considerando um regime de operação de 7 horas por dia, foi escolhido o grupo gerador Leão modelo LPG45 da empresa Leão Energia, por meio de cotação realizada no mês de novembro de 2020. A especificações do grupo gerador são mostradas na Tabela 1 . 
Tabela 1 - Especificações do grupo gerador Leão LPG45.

$\begin{array}{cc}\text { Potência em contínuo } & 45 \mathrm{~kW} / 56 \mathrm{kVA} \\ \text { Tensão } & 220 / 127 \mathrm{~V} \\ \text { Frequência nominal } & 60 \mathrm{~Hz} \\ \text { Eficiência elétrica } & 34 \% \\ \text { Fator de potência } & 0,8 \\ \text { Consumo de combustível } & 22 \mathrm{~m} 3 / \mathrm{h}\end{array}$

Fonte: Leão Energia (2020).

\section{Viabilidade Econômica}

Considerando que o sistema gerador seja a única fonte de suprimento da demanda de energia no local é possível estimar os benefícios com a geração de energia elétrica de acordo com a renda que se deixa de transferir para a concessionária de energia elétrica, quando esta é produzida internamente. Dessa maneira, o benefício obtido está relacionado ao consumo de energia elétrica em função do tempo de operação do sistema e da tarifa de energia elétrica paga pelo proprietário, o que pode ser traduzido através da Equação (1) (CERVI et al., 2010).

$B_{E E}=\left(E_{C} \times T\right) T_{E E}$

onde $B_{E E}$ representa o benefício com a geração de energia elétrica (R $\left.\$ / a n o\right), E_{C}$ é a energia elétrica consumida $(\mathrm{kWh}), T$ é o tempo de operação (k/ano), e $T_{E E}$ representa a tarifa de energia elétrica $(\mathrm{R} \$ / \mathrm{kWh})$.

A propriedade está classificada com tarifa horo-sazonal branca, pela concessionária de energia elétrica, inserida no grupo B2 Rural, que se caracteriza pela aplicação de tarifas diferenciadas em horários de ponta ou fora de ponta, conforme consumo de energia. $\mathrm{O}$ preço estabelecido pela concessionária local no horário de ponta (das 18 às $22 \mathrm{~h}$ ) e fora de ponta (demais horas do dia) é de é de $\mathrm{R} \$ 0,75$ e $\mathrm{R} \$ 0,20$ por $\mathrm{kWh}$, respectivamente.

O investimento inicial pode ser classificado como o custo necessário para a implantação das instalações, equipamentos e suas manutenções. Por meio das pesquisas e cotações descritas a seguir, a estimativa do valor do investimento inicial é realizada através da Equação (2):

$I=C_{M}+M_{O}$

onde $I$ representa o valor do investimento inicial $(\mathrm{R} \$), C_{M}$ representa os custos relativos à materiais e equipamentos, e $M_{O}$ representa os custos de instalação e manutenção. Os custos relativos à equipamentos são definidos através da cotação para o sistema gerador de energia, como mostra a Tabela 2. 
Tabela 2 - Orçamento do sistema gerador.

\begin{tabular}{ccccc}
\hline Descrição & Qtd. & Unit. Bruto & Unid. Líq. & Valor Total \\
\hline $\begin{array}{c}\text { GMG Biogás LGB50 - FPT N45 SM6 } \\
\text { 60 Hz }\end{array}$ & 1 & $117.743,13$ & $117.743,13$ & $117.743,13$ \\
$\begin{array}{c}\text { Quadro de transferência automático - } \\
\text { QTA 160A CT }\end{array}$ & 1 & $9.278,50$ & $9.278,50$ & $9.278,50$ \\
\hline Total dos itens & & & $\mathbf{1 2 7 . 0 2 1 , 6 3}$ & \\
\hline
\end{tabular}

Fonte: Leão Energia (2020).

Além disso, são avaliados os elementos envolvidos para a construção do biodigestor em termos econômicos por meio de um levantamento bibliográfico (MARTINS e OLIVEIRA, 2011, 2013; CERVI et al., 2010; SOUZA et al., 2019) e dos custos médios de insumos e composições encontrados por meio da tabela SINAPI (Sistema Nacional de Pesquisas de Custos e Índices da Construção Civil) para o mês de novembro de 2020. Tem-se assim, de maneira simplificada, os custos de implantação e construção para o biodigestor conforme mostra a Tabela 3.

Tabela 3 - Custos de construção para o biodigestor.

\begin{tabular}{ccccc}
\hline Natureza do serviço & Unidade & Preço unitário & $\begin{array}{c}\text { Volume ou } \\
\text { Comprimento } \\
\text { utilizado }\end{array}$ & Preço total \\
\hline $\begin{array}{c}\text { Escavação e } \\
\text { drenagem profunda } \\
\text { com corte trapezoidal }\end{array}$ & $\mathrm{m}$ & 184,50 & 20 & $3.690,00$ \\
$\begin{array}{c}\text { Escoramento e } \\
\text { Alvenaria }\end{array}$ & $\mathrm{m}^{3}$ & 30,29 & 850 & $25.746,50$ \\
$\begin{array}{c}\text { Fornecimento e } \\
\text { Assentamento de } \\
\text { tubos de PVC Rígido }\end{array}$ & $\mathrm{m}$ & 45,38 & 35 & $1.588,30$ \\
$\begin{array}{c}\text { Soldáveis 150 mm de } \\
\text { diâmetro }\end{array}$ & & & & \\
Manta Geotêxtil & $\mathrm{m}^{2}$ & & & \\
\hline Total & & 5,65 & 300 & $1.695,00$ \\
\hline
\end{tabular}

Fonte: SINAPI (2020).

Assim, com o auxílio da Equação (2), os custos de investimento inicial em função dos custos de instalação, construção e equipamentos do sistema gerador são estimados em R \$159.741,43.

Os custos anuais do sistema podem ser definidos levando em consideração os custos fixos relacionados aos juros sobre o capital fixado, depreciação e custos variáveis referentes à manutenção e operação (SOUZA et al., 2019). A depreciação pode ser calculada com base no valor residual dos equipamentos e materiais utilizados, ou seja, no valor esperado do item ao final de sua vida útil. Esse cálculo é feito com base na Equação (3): 
$D=\frac{C_{i}-\left(C_{i} \times V_{r}\right)}{V_{u}}$

onde $D$ representa a depreciação anual (R\$/ano), $C_{i}$ é o custo com materiais depreciáveis (R\$), $V_{r}$ representa o valor residual (\%), e $V_{u}$ a vida útil. Considerando o valor residual de $5 \%$ para todos os materiais envolvidos, os custos de depreciação anuais são apresentados na Tabela 4.

Tabela 4 - Custos de depreciação.

\begin{tabular}{ccccc}
\hline Itens & $\begin{array}{c}\text { Valor inicial / } \\
\mathbf{R} \$\end{array}$ & $\begin{array}{c}\text { Vida útil / } \\
\text { anos }\end{array}$ & $\begin{array}{c}\text { Valor } \\
\text { residual } \\
/ \%\end{array}$ & $\begin{array}{c}\text { Depreciação / } \\
\mathbf{R} \mathbf{\text { ano-1 }}\end{array}$ \\
\hline $\begin{array}{c}\text { Escoramento e alvenaria } \\
\text { Tubulação }\end{array}$ & $22.323,73$ & 20 & 5 & $1.222,96$ \\
Manta Geotêxtil & $1.588,30$ & 10 & 5 & 150,89 \\
GMG Biogás LGB50-FPT & $1.695,00$ & 10 & 5 & 161,03 \\
N45 SM6 60 Hz & $117.743,13$ & 20 & 5 & $5.592,80$ \\
Quadro de transferência & & & & \\
automático- QTA 160A & $9.278,50$ & 20 & 5 & 440,73 \\
CT & & & & $\mathbf{7 . 5 6 8 , 4 0}$ \\
\hline Total & & & & \\
\hline
\end{tabular}

Fonte: Brito (2021).

Os juros sobre o capital investido, também conhecido como o custo de oportunidade, pode ser definido em relação ao capital médio durante a vida útil dos bens, a uma taxa de juros de $2 \%$, correspondente a taxa de rendimento atual do Sistema Especial de Liquidação e Custódia - SELIC (Banco Central do Brasil, 2020). Pode ser calculado conforme equação (4):

$J=C_{i} \times T_{J A}$

onde $J$ representa os juros sobre o capital investido $(\mathrm{R} \$), C_{i}$ é custo inicial de matérias $(\mathrm{R} \$)$ e $T_{J A}$ a taxa anual de juros (\%). Tomando o valor de $2 \%$ como referência, os juros calculados são mostrados na Tabela 5 . 
Tabela 5 - Juros sobre o capital investido.

\begin{tabular}{cccc}
\hline Itens & $\begin{array}{c}\text { Valor inicial / } \\
\mathbf{R} \$\end{array}$ & $\begin{array}{c}\text { Taxa de juros / \% } \\
\mathbf{a n o}^{-\mathbf{1}}\end{array}$ & $\begin{array}{c}\text { Juros / } \\
\mathbf{R} \mathbf{\text { ano }}\end{array}$ \\
\hline Escoramento e alvenaria & $22.323,73$ & 2 & 514,93 \\
Tubulação & $1.588,30$ & 2 & 31,77 \\
Manta Geotêxtil & $1.695,00$ & 2 & 33,9 \\
GMG Biogás LGB50 - FPT & $117.743,13$ & 2 & $2.354,86$ \\
N45 SM6 60 Hz & & 2 & 185,57 \\
Quadro de transferência & $9.278,50$ & & $\mathbf{3 . 1 2 1 , 0 3}$ \\
\hline automático - QTA 160A CT & & & \\
\hline Total & & & \\
\hline
\end{tabular}

Fonte: Adaptado de SINAPI (2020) e Leão Energia (2020).

É necessário que seja previsto também um plano de manutenção e manejo adequados para o biodigestor, de modo a manter os padrões de qualidade do biogás e atender as condições de potência de saída nominal dos equipamentos, assim como o atendimento da carga de consumo desejada. Sendo assim, segundo Souza et al. (2019), para estimar a manutenção do biodigestor é preciso antes estimar o intervalo de manutenção de seus componentes, como por exemplo o serviço de troca de óleo e lubrificação em função do tempo de operação. Dessa forma, são levados em conta os materiais utilizados e a estimativa do valor de assistência técnica necessária, de modo que o gasto anual com a manutenção possa ser obtido através da Equação (5):

$G_{M}=\left(\frac{T}{I_{M}}\right) A_{T}$

onde $G_{M}$ representa os gastos com manutenção em reais por ano, $T$ representa o tempo de operação do sistema em horas por ano, $I_{M}$ é o intervalo de manutenção dos componentes em horas por unidade, e $A_{T}$ representa o valor da assistência técnica em reais por unidade.

Simulando a atuação diária de um profissional responsável pelo ligamento e limpeza esporádica do biodigestor, para a remoção do lodo precipitado, o cálculo com gastos de mão de obra para a manutenção do sistema pode ser obtido por meio da Equação (6):

$G_{M O}=T G_{S}$

onde $G_{M O}$ representa os gastos com mão de obra para operação do sistema em reais por ano, $T$ é o tempo de operação em horas por ano e $G_{S}$ representa os gastos com salário em reais por hora.

A Tabela 6 apresenta os custos com a manutenção preventiva do biodigestor, levando em consideração as variáveis da Equação (5) e com base nos valores de assistência técnica cobrados por esses serviços na região sul da Bahia. O tempo de operação do sistema ( $T$ ) é avaliado em relação ao regime de operação de 7 horas por dia, excetuando-se domingos e feriados. Estima-se um período de 26 dias por mês e 312 dias por ano, o que resulta em 2184 horas de operação por ano. 
Tabela 6 - Manutenção preventiva do sistema.

\begin{tabular}{|c|c|c|c|}
\hline Componente & Intervalo / horas & $\begin{array}{c}\text { Custo de } \\
\text { Manutenção / } \\
\text { R\$ }\end{array}$ & $\begin{array}{c}\text { Custo Anual de } \\
\text { Manutenção / } \\
\text { R\$ } \\
\end{array}$ \\
\hline Lubrificante & Troca a cada 100 horas & 80,00 & $1.747,20$ \\
\hline \multirow{2}{*}{ Filtro de Óleo } & $\begin{array}{c}\text { Troca de óleo a cada } 400 \\
\text { horas }\end{array}$ & 52,00 & 283,92 \\
\hline & $\begin{array}{l}\text { Limpeza dos filtros a } \\
\text { cada } 200 \text { horas }\end{array}$ & 15,00 & 163,80 \\
\hline $\begin{array}{c}\text { Sistema de } \\
\text { Combustível }\end{array}$ & $\begin{array}{l}\text { Limpeza da válvula de } \\
\text { gás a cada } 2.000 \text { horas }\end{array}$ & 15,00 & 16,38 \\
\hline Filtro de Ar & $\begin{array}{l}\text { Troca do filtro de ar a } \\
\text { cada } 2.000 \text { horas }\end{array}$ & 86,00 & 93,91 \\
\hline $\begin{array}{c}\text { Sistema de } \\
\text { Refrigeração }\end{array}$ & $\begin{array}{c}\text { Troca do líquido } \\
\text { refrigerante, da correia } \\
\text { dentada e do esticador da } \\
\text { correia a cada } 1.000 \text { horas }\end{array}$ & 220,00 & 480,48 \\
\hline \multirow{2}{*}{ Alternador } & $\begin{array}{l}\text { Troca da correia e do jogo de } \\
\text { velas a cada } 1.000 \text { horas }\end{array}$ & 200,00 & 436,80 \\
\hline & $\begin{array}{c}\text { Troca dos rolamentos a cada } \\
2.000 \text { horas }\end{array}$ & 100,00 & 109,20 \\
\hline $\begin{array}{l}\text { Rolamento do } \\
\text { Gerador }\end{array}$ & Lubrificar a cada 1.000 horas & 20,00 & 43,68 \\
\hline Total & & & $\mathbf{3 . 3 7 5 , 3 7}$ \\
\hline
\end{tabular}

Fonte: Brito (2021).

Estimando um tempo de operação de 200 horas por ano para a mão de obra de operação do sistema, referente às limpezas esporádicas, acionamento e desligamento do sistema, tem-se um custo anual com mão de obra de $\mathrm{R} \$ 600,00$. Assim, os gastos totais com manutenção e instalação do sistema resultam em R \$ 3.975,37 ao ano. Assim, os custos anuais de depreciação, juros sobre o capital investido e operação do sistema podem ser então resumidos na Tabela 7. 
Tabela 7 - Custos totais para operação do Sistema.

\begin{tabular}{cc}
\hline Itens de Custo & R\$ / ano \\
\hline Depreciação & $7.568,40$ \\
Juros & $3.121,03$ \\
Mão de obra para operação do sistema & 600,00 \\
Manutenção preventiva do grupo gerador & $3.375,37$ \\
\hline Total & $\mathbf{1 4 . 6 6 4 , 8 0}$ \\
\hline
\end{tabular}

Fonte: Brito (2021).

Definidos esses parâmetros, podem ser avaliadas as condições de rentabilidade do empreendimento por meio dos indicadores econômicos: Valor Presente Líquido (VPL), Taxa Interna de Retorno (TIR) e Payback Simples (PS).

\section{Indicadores Econômicos de Viabilidade}

Segundo Neto (1992), o VPL reflete a riqueza em valores absolutos do investimento por meio da diferença entre o valor presente das entradas de caixa e o valor presente das saídas. Isto é, um indicador que permite avaliar a viabilidade econômica do projeto durante seu período de vida útil, considerando o valor atual dos benefícios menos o valor atual dos custos, podendo ser calculado através da Equação (7):

$V P L=\sum_{i=0}^{n} \frac{B_{i}-C_{i}}{(1+r)^{i}}$

onde $B_{i}$ representa os benefícios do projeto em unidades monetárias, no ano $i, C_{i}$ representa os custos do projeto, também em unidades monetárias no ano $i, r$ representa uma taxa de desconto $(\%)$, $i$ é o contador de tempo (em anos), e $n$ representa o período de vida útil do investimento, em anos.

Sendo assim, se o VPL for positivo, significa que foi recuperado o investimento inicial aplicado de acordo com uma taxa mínima de atratividade (TMA) - adotada nesse trabalho como $2 \%$ ao ano - e o empreendimento poderá ser considerado viável.

A Taxa Interna de Retorno (TIR) requer o cálculo da taxa que zera o valor presente líquido (VPL), isto é, representa a taxa de desconto que iguala num único momento os fluxos de entrada com os fluxos de saída (NETO, 1992). De modo que possa calculado por meio da equação:

$\sum_{i=0}^{n} \frac{B_{i}-C_{i}}{(1+r)^{i}}=0$

onde as variáveis são análogas as da Equação (7).

Com base nesse método, se a TIR exceder a taxa mínima de atratividade (TMA) o investimento é classificado como economicamente atraente; caso contrário há recomendação técnica de rejeição (NETO, 1992).

O período de recuperação do capital, conhecido como Payback Simples (PS), consiste essencialmente em determinar o tempo necessário para que o capital investido no projeto seja recuperado por meio dos benefícios econômicos gerados (NETO, 1992).

Sendo assim, considerando o período de operação do conjunto das $8 \mathrm{~h}$ às 15:30 h, durante 312 dias por ano, os benefícios gerados com a produção de energia elétrica podem ser considerados referentes a tarifa fora de ponta $(\mathrm{R} \$ 0,20 \mathrm{kWh}-1)$, resultando no valor de $\mathrm{R} \$ 25.415,87$ ano-1. Por meio do cálculo do consumo médio diário de energia elétrica, é possível extrair valores baseados 
nas informações do histórico de consumo e verificar as respectivas relações com os indicadores econômicos considerados. Isso pode ser visto na Tabela 8.

Tabela 8 - Simulação do consumo médio de energia elétrica para utilização de 7 h/dia.

\begin{tabular}{cccccc}
\hline $\begin{array}{c}\text { Consumo médio de } \\
\text { energia / kWh }\end{array}$ & $\begin{array}{c}\text { Tempo } \\
\text { de } \\
\text { operação } \\
\text { / h/dia }\end{array}$ & $\begin{array}{c}\text { Benefício / } \\
\text { R\$/ano }\end{array}$ & VPL / R\$ & TIR / \% & $\begin{array}{c}\text { PS / } \\
\text { anos }\end{array}$ \\
\hline 43,23 & 7 & $\mathrm{R} \$ 19.238,81$ & $\mathrm{R} \$ 12.816,45$ & $4 \%$ & 8,3 \\
49,27 & 7 & $\mathrm{R} \$ 21.926,81$ & $\mathrm{R} \$ 36.488,23$ & $6 \%$ & 7,3 \\
57,11 & 7 & $\mathrm{R} \$ 25.415,87$ & $\mathrm{R} \$ 67.214,52$ & $9 \%$ & 6,3 \\
58,67 & 7 & $\mathrm{R} \$ 26.110,13$ & $\mathrm{R} \$ 73.328,43$ & $10 \%$ & 6,1 \\
68,95 & 7 & $\mathrm{R} \$ 30.685,07$ & $\mathrm{R} \$ 113.617,49$ & $14 \%$ & 5,2 \\
71,72 & 7 & $\mathrm{R} \$ 31.917,82$ & $\mathrm{R} \$ 124.473,59$ & $15 \%$ & 5,0 \\
\hline
\end{tabular}

Fonte: Brito (2021).

Os indicadores mostram que o investimento é viável economicamente, mantendo-se inalterado o período de utilização da planta. Observando o consumo diário mínimo de $43 \mathrm{kWh}$, no período de novembro de 2019 a novembro de 2020, percebe-se um benefício anual com a geração de energia de $\mathrm{R} \$ 19.238,81$, com VPL assumindo um valor positivo de $\mathrm{R} \$ 12.816,45$ e um retorno do investimento em aproximadamente 8 anos. Os benefícios anuais podem alcançar o valor de R\$31.917,82, com o consumo máximo diário do período, apresentando também um VPL positivo, uma TIR significativamente maior do que a Taxa Mínima de Atratividade (TMA), e um Payback simples reduzido a 5 anos, indicando o pagamento total do investimento.

Também foi simulada a utilização do grupo gerador de energia no horário de ponta, das 18 às $22 \mathrm{~h}$, onde há elevação da tarifa de energia elétrica cobrada pela concessionária de energia, no valor de R\$ 0,75 kWh-1, conforme os dados da Tabela 9.

Tabela 9 - Benefícios econômicos com a geração de energia elétrica no horário de ponta.

\begin{tabular}{ccc}
\hline $\begin{array}{c}\text { Consumo médio de } \\
\text { energia / kWh }\end{array}$ & $\begin{array}{c}\text { Tempo de operação do } \\
\text { conjunto gerador no horário } \\
\text { de ponta / h/dia }\end{array}$ & $\begin{array}{c}\text { Benefício com geração de } \\
\text { energia elétrica / R\$/ano }\end{array}$ \\
\hline 43,23 & 4 & $\mathrm{R} \$ 10.993,60$ \\
49,27 & 4 & $\mathrm{R} \$ 12.529,61$ \\
57,11 & 4 & $\mathrm{R} \$ 14.523,36$ \\
58,67 & 4 & $\mathrm{R} \$ 14.920,07$ \\
68,95 & 4 & $\mathrm{R} \$ 17.534,33$ \\
71,72 & 4 & $\mathrm{R} \$ 18.238,75$ \\
\hline
\end{tabular}

Fonte: Brito (2021).

Nota-se que o benefício gerado com a substituição da energia elétrica da concessionária pela produzida no biodigestor no horário de ponta revela aumentos consideráveis em relação à proporção do tempo de operação anterior. Utilizando a tarifa de horário de ponta, para o consumo de $43 \mathrm{kWh}$ de energia elétrica tem-se um benefício de $\mathrm{R} \$ 10.993,60$ por ano, podendo alcançar o valor de $\mathrm{R} \$ 18.238,75$ anuais, quando o consumo é de aproximadamente $72 \mathrm{kWh}$.

Assim, também foram simulados os benefícios obtidos considerando um período de operação da planta de 7 horas por dia, fora do horário de ponta, com as 4 horas adicionais do período de ponta, como mostra a Tabela 10. 
Tabela 10 - Simulação do consumo médio de energia elétrica para utilização de $11 \mathrm{~h} /$ dia.

\begin{tabular}{ccccccc}
\hline $\begin{array}{c}\text { Consumo } \\
\text { médio de } \\
\text { energia / kWh }\end{array}$ & $\begin{array}{c}\text { Tempo de } \\
\text { operação / } \\
\text { h/dia }\end{array}$ & $\begin{array}{c}\text { Benefício / } \\
\text { R\$/ano }\end{array}$ & VPL / R\$ & TIR / \% & PS / anos \\
\hline 43,23 & 11 & $\mathrm{R} \$ 30.232,41$ & $\mathrm{R} \$ 109.631,14$ & $14 \%$ & 5,3 \\
49,27 & 11 & $\mathrm{R} \$ 34.456,41$ & $\mathrm{R} \$ 146.829,61$ & $17 \%$ & 4,6 \\
57,11 & 11 & $\mathrm{R} \$ 39.939,23$ & $\mathrm{R} \$ 195.113,82$ & $21 \%$ & 4,0 \\
58,67 & 11 & $\mathrm{R} \$ 41.030,20$ & $\mathrm{R} \$ 204.721,40$ & $22 \%$ & 3,9 \\
68,95 & 11 & $\mathrm{R} \$ 48.219,40$ & $\mathrm{R} \$ 268.032,77$ & $28 \%$ & 3,3 \\
71,72 & 11 & $\mathrm{R} \$ 50.156,57$ & $\mathrm{R} \$ 285.092,38$ & $29 \%$ & 3,2 \\
\hline
\end{tabular}

Fonte: Brito (2021).

São observadas mudanças significativas à medida que o tempo de operação do sistema é incrementado e a tarifa de utilização da energia elétrica é alterada. Pode-se perceber que mesmo com um consumo médio de $57 \mathrm{kWh}$, é possível obter um benefício anual de $\mathrm{R} \$ 39.939,23$ e uma redução do período de payback para 4 anos, podendo alcançar o retorno total do investimento em até 3 anos, com a utilização do consumo máximo de $72 \mathrm{kWh}$. Sendo assim, pode-se inferir que quanto maior o consumo de energia elétrica, maiores serão os benefícios alcançados com a geração autônoma de energia e consequentemente menor será o tempo necessário para o pagamento do investimento inicial, com taxas de retorno também mais atrativas.

Em comparação, CERVI et al (2010) estimou a viabilidade econômica de um sistema biointegrado para geração de eletricidade a partir do aproveitamento de dejetos de suínos em uma agroindústria. O investimento inicial para implantação foi estimado em $\mathrm{R} \$ 51.537,17$, e os custos anuais do sistema foram de $\mathrm{R} \$ 11.465,37$, concluindo que o sistema de produção de biogás é viável do ponto de vista econômico, se o consumo de energia elétrica for igual ou superior a $35 \mathrm{kWh}$ por dia, em média. Foram assim relacionados os níveis de consumo aos indicadores de viabilidade, onde os consumos médios de 20 e $40 \mathrm{kWh}$ apresentaram VPL de R \$ 49.066,37 e R \$29.015,32 ao ano, respectivamente, e uma TIR de 16,24\% apenas para o consumo de $40 \mathrm{kWh}$, apresentando payback simples de 5,79 anos.

SOUZA et al (2019) também avaliou a viabilidade econômica de um biodigestor para geração de eletricidade, com a utilização do biogás proveniente de dejetos de bovinos em confinamento em uma propriedade rural no Paraná. Foi estimado o investimento de $\mathrm{R} \$ 49.155,32$, custos anuais de $\mathrm{R} \$ 10.961,17$ e benefícios obtidos com a substituição da energia elétrica comprada da concessionária, simulando diferentes cenários para as faixas de consumo de 20 a $40 \mathrm{kWh}$. O projeto foi considerado viável, com VPL de R $\$ 16.221,28$ e R $\$ 160.395,86$, TIR de $13 \%$ e $19 \%$, e retorno do investimento obtido no ano 7 e ano 2 para os consumos de 20 e $40 \mathrm{kWh}$ respectivamente.

Os cálculos dos indicadores econômicos realizados nos trabalhos de Cervi et al. (2010) e Souza et al. (2019) levaram em consideração a taxa básica de juros da economia brasileira na época, que era de 5,64\% ao ano e 6,5\% ao ano, respectivamente. É importante salientar que nesse trabalho foi utilizada uma taxa mínima de atratividade de $2 \%$ referente à taxa atual de juros da economia brasileira (ou taxa Selic). Uma comparação entre os indicadores econômicos principais, em relação às referências citadas pode ser vista no gráfico da Figura 2. 


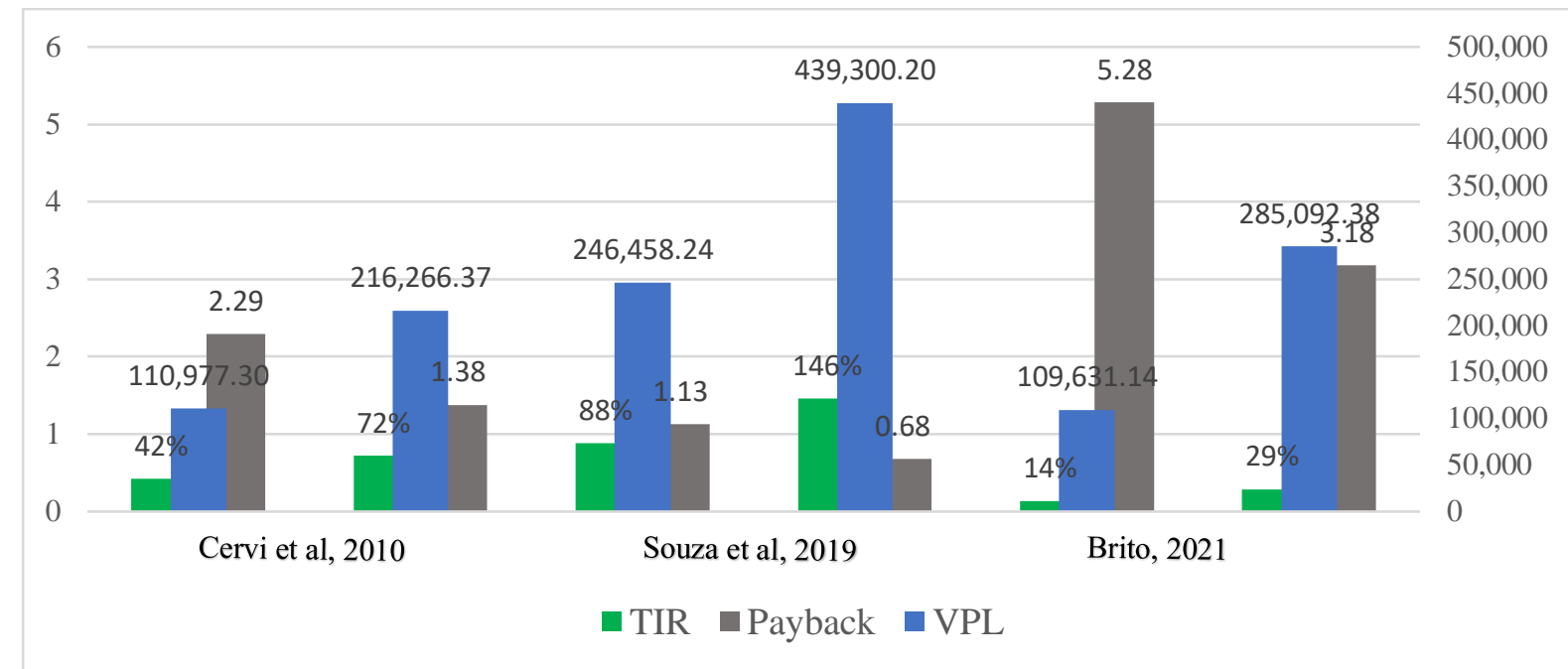

Figura 2 - Comparação dos valores entre os indicadores econômicos observados na literatura com o presente trabalho.

Fonte: Brito (2021).

No gráfico da Figura 2 são avaliados o valor presente líquido (VPL), taxa interna de retorno (TIR) e o payback simples (PS) para os consumos médios de energia elétrica diários que foram obtidos nesse trabalho (referente ao histórico de consumo da Fazenda São José), afim de obter uma comparação mais consistente com os resultados obtidos da literatura. Também foram analisados os indicadores econômicos referentes aos consumos de 20 e $40 \mathrm{kWh}$, mas assim como acontece em Cervi et al. (2010) o VPL e a TIR apresentam indicativos de inviabilidade para o projeto, tendo em vista os baixos níveis de consumo de energia elétrica.

Os valores mais baixos de VPL e TIR são justificados pela grande diferença no valor de investimento inicial que este projeto necessita ( $\mathrm{R} \$ 159.741,43)$, em comparação com os demais, em virtude dos preços da tecnologia embarcada nos equipamentos (Tabela 2). No entanto, para os níveis de consumo entre 43 e $72 \mathrm{kWh}$ todos os indicadores apontam para a viabilidade do projeto com valores bem próximos nas três circunstâncias analisadas.

O biogás produzido diariamente será utilizado para geração de energia elétrica por meio de um grupo gerador capaz de suprir a carga de energia exigida pela localidade. Então, faz-se necessário que o estudo dos equipamentos a serem utilizados nessa tarefa seja feito em consonância com a análise do histórico anual de consumo de energia elétrica da fazenda São José (onde é aplicado o estudo). A variação dos benefícios obtidos para a faixa de consumo de 43 a $72 \mathrm{kWh}$ para os cenários avaliados podem ser vistos no gráfico da Figura 3.

Como mencionado antes, os benefícios estão relacionados ao consumo de energia elétrica em função do tempo de operação da planta e da tarifa de energia elétrica paga pelo proprietário, descrito pela Equação (1). Cervi et al. (2010) considera tarifas tanto no período "seco" (R\$ 0,165 kWh-1, durantes 7 meses) quanto no período "úmido" ( $\mathrm{R} \$ 0,151 \mathrm{kWh}^{-1}$, durante 5 meses), ambas no horário fora de ponta. Enquanto Souza et al. (2019) leva em conta apenas a tarifa anual de R $0,41782 \mathrm{kWh}^{-}$ 1, também fora do horário de ponta. 


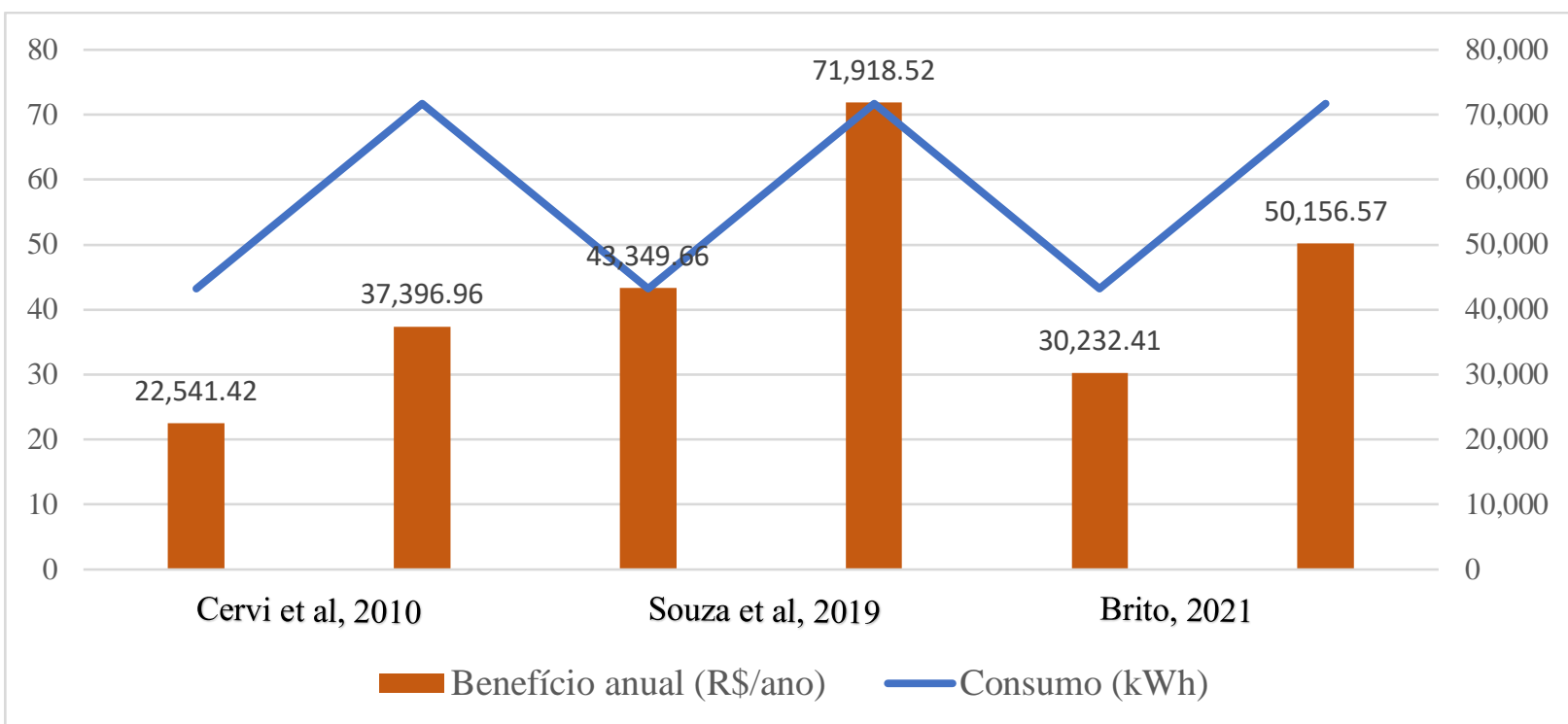

Figura 3 - Benefícios anuais estimados para diferentes níveis de consumo de energia elétrica.

Fonte: Brito (2021).

A tarifa para o consumo de energia elétrica considerada nesse trabalho é de $\mathrm{R} \$ 0,20$ para o período fora de ponta. Com ela foi possível obter os benefícios anuais de $\mathrm{R} \$ 30.232,41$ e R\$ 50.156,57 para os consumos mínimos e máximos de 43,23 e 71,72 kWh, respectivamente. Percebe-se que apesar de possuir uma tarifa mais baixa em relação aos outros autores analisados, os benefícios gerados são muito próximos daqueles obtidos nas outras referências estudadas, tendo em vista a mesma faixa de consumo de eletricidade.

\section{Conclusão}

Dessa forma, é possível perceber que os valores obtidos através das simulações podem ser validados pelos resultados aproximados obtidos da literatura. Além disso, é importante salientar que as simulações aqui realizadas envolvem simplificações que podem decorrer em diferenças significativas na aplicação efetiva do projeto. Outras variáveis de custo poderiam ser consideradas e os benefícios da geração de energia são diretamente dependentes da demanda e período de consumo avaliados, nesse caso.

Também poderiam ser considerados os benefícios obtidos com a venda e uso do biofertilizante, visto como subproduto da fermentação, e com os créditos de carbono gerados que poderiam ser certificados pela redução de gases do efeito estufa, gerando ainda mais renda para a propriedade. Portanto, o projeto demonstra ser potencialmente viável do ponto de vista econômico, sendo observadas as condições técnicas de demanda, especificidades da localidade, equipamentos, materiais utilizados e benefícios considerados.

\section{Agradecimento}

Os autores agradecem ao CNPq e FAPESB pelo suporte via bolsas. 


\section{Referencias}

Balanço Energético Nacional (BEN). (2019). Ano base 2018. Empresa de Pesquisa Energética EPE (Brasil). Rio de Janeiro: Ministério de Minas e Energia. Anual.

Banco Central do Brasil. (2020). https://www.bcb.gov.br/controleinflacao/taxaselic.

Boletim de Conjuntura Econômica e Social. (2019). Microrregião Ilhéus-Itabuna: Departamento de Economia - Universidade Estadual de Santa Cruz - Anual. ISSN 2525-5134.

Brito, R. C. F., \& Sales, J. H. O. (2019). Modelagem de um Biogerador tipo Marinha para Produção de Energia Elétrica Usando o Cacau como Aditivo. International Congress of Mechanical Engeneering (COBEM), Ilhéus, Brasil. 10.26678/ABCM.CREEM2019.CRE2019-0194.

Brito, R. C. F. (2021). Modelagem de um Biogerador tipo Marinha para Análise de viabilidade de Autonomia Energética em uma Fazenda de Cacau. Dissertação de Mestrado, Universidade Estadual de Santa Cruz, Ilhéus, BA, Brasil.

Cervi, R. G., Esperancini, M. S. T., Bueno, O. C. (2010). Viabilidade Econômica da Utilização do Biogás Produzido em Granja Suinícola para Geração de Energia Elétrica. Engenharia Agrícola, Jaboticabal, 30(5), 831-844. https://doi.org/10.1590/S0100-69162010000500006.

Cortez L. A. B. et al. (2008). Biomassa para Energia. UNICAMP.

Cunha, E. S, et. al. (2021). Determination of thermophysical properties of cupuassu (Theobroma grandiflorum) dry almonds. The Journal of Engineering and Exact Sciences - jCEC, 07(02). https://doi.org/10.18540/jcecvl7iss2pp11955-01-12e.

IBGE - Instituto Brasileiro de Geografia e Estatística, Caixa Econômica Federal. (2020). Sistema Nacional de Pesquisas de Custos e Índices da Construção Civil - SINAPI. Documentação técnica. Disponível em: https://www.caixa.gov.br/poder-publico/modernizacaogestao/sinapi/. Acesso em: nov. 2020.

Leão Energia Indústria de Geradores LTDA. (2020). Catálogo de motores geradores. Unidade Industrial de Aves da LAR.

Martins, F. M., De Oliveira, P. A. V. (2011). Análise econômica da geração de energia elétrica a partir do biogás na suinocultura. Energia na Agricultura, Jaboticabal, 31(3), 477-486. https://doi.org/10.1590/S0100-69162011000300008.

Neto, A. A. (1992). Os métodos quantitativos de análise de investimentos. Caderno de Estudos. Fundação Instituto de Pesquisas Contábeis, Atuariais e Financeiras, São Paulo, 1(6). https://doi.org/10.1590/S1413-92511992000300001.

Sales, J. H. de O., Brito, R. C. F. (2022). Biogerador para uma Fazenda de Cacau. The Journal of Engineering and Exact Sciences, 8(1), 13736-01. https://doi.org/10.18540/jcecvl8iss1pp13736-01-12e.

Sales, J. H., Suzuki, A. T. (2021). Thermal Ellipsoidal model of Cocoa almond. Brazilian Journal of Development, Curitiba, 7(3), 31618-31633. https//doi.org/10.34117/bjdv7n3-740.

Sales, J. H. O., Lima, G. P. A. (2020). Procedimento didático para a modelagem computacional da amêndoa do cupuaçu em coordenadas cartesianas. Revista Brasileira de Ensino de Ciência e Tecnologia, Ponta Grossa, 13(3), 1-19. https://doi.org/10.3895/rbect.v13n3.8517.

Salomon, K. R. (2007). Avaliação Técnico-Econômica e Ambiental da Utilização do Biogás Proveniente da Biodigestão da Vinhaça em Tecnologias para Geração de Eletricidade. Tese de doutorado, Universidade Federal de Itajubá, Itajubá, MG, Brasil.

Souza, D. M., Silva, V. H, Castro, M. A. S., Castro, G. B. S. (2019). Viabilidade Econômica da Implantação de um Biodigestor em uma Propriedade no Munícipio de Ribeirão Claro - PR. Revista Meio ambiente e desenvolvimento sustentável, Atena Editora, 1(4), 186-198. https://doi.org/10.22533/at.ed.54319111115. 